\title{
Nitrogen-doped carbon nanotubes on silicon carbide as a metal-free catalyst
}

\author{
Cuong Duong-Viet ${ }^{\mathrm{a}, \mathrm{b}}$, Housseinou Ba ${ }^{\mathrm{a}}$, Yuefeng Liu ${ }^{\mathrm{a}, *}$, Lai Truong-Phuoc ${ }^{\mathrm{a}}$, Jean-Mario Nhut ${ }^{\mathrm{a}}$, \\ Cuong Pham-Huu a,\# \\ a Institute of Chemistry and Processes for Energy, Environment and Health (ICPEES), ECPM, UMR 7515 du CNRS - University of Strasbourg, \\ 25 rue Becquerel, 67087 Strasbourg Cedex 02, France \\ ${ }^{\mathrm{b}}$ Hanoi University of Mining and Geology, Dong Ngac, Tu Liem, Hanoi, Viet Nam
}

\section{A R T I C L E I N F O}

Article history:

Received 31 March 2014

Accepted 21 April 2014

Published 20 June 2014

\section{Keywords:}

Nitrogen-doped carbon nanotubes

Silicon carbide

Selective oxidation

$\mathrm{H}_{2} \mathrm{~S}$

Dehydrogenation

Ethylbenzene

\begin{abstract}
A B S T R A C T
A hierarchical metal-free catalyst consisting of nitrogen-doped carbon nanotubes decorated onto a silicon carbide (N-CNTs/SiC) macroscopic host structure was prepared. The influence of N-CNTs incorporation on the physical properties of the support was evaluated using different characterization techniques. The catalyst was tested as a metal-free catalyst in the selective oxidation of $\mathrm{H}_{2} \mathrm{~S}$ and steam-free dehydrogenation of ethylbenzene. The N-CNTs/SiC catalyst exhibited extremely good desulfurization performance compared to a $\mathrm{Fe}_{2} \mathrm{O}_{3} / \mathrm{SiC}$ catalyst under less conducive reaction conditions such as low temperature, high space velocity, and a low $\mathrm{O}_{2}$-to- $\mathrm{H}_{2} \mathrm{~S}$ molar ratio. For the dehydrogenation of ethylbenzene, a higher dehydrogenation activity was obtained with the N-CNTs/SiC catalyst compared to a commercial $\mathrm{K}-\mathrm{Fe} / \mathrm{Al}_{2} \mathrm{O}_{3}$ catalyst. The $\mathrm{N}-\mathrm{CNTs} / \mathrm{SiC}$ catalyst also displayed good stability as a function of time on stream for both reactions, which was attributed to the strong anchoring of the nitrogen dopant in the carbon matrix. The extrudate shape of the SiC support allowed the direct macroscopic shaping of the catalyst for use in a conventional fixed-bed reactor without the problems of catalyst handling, transportation, and pressure drop across the catalyst bed that are encountered with nanoscopic carbon-based catalysts.
\end{abstract}

(C) 2014, Dalian Institute of Chemical Physics, Chinese Academy of Sciences. Published by Elsevier B.V. All rights reserved.

\section{Introduction}

The last decade has seen increasing research on the development of metal-free catalysts for several catalytic applications such as oxygen reduction reaction (ORR) [1-3], selective steam-free dehydrogenation and oxidative dehydrogenation [4-7], transesterification [8,9], and selective oxidation [10-12]. Nitrogen-doped carbon nanotubes (N-CNTs) were the most studied metal-free catalysts [13-15]. The very similar size between the nitrogen atom and carbon atom allows an easy insertion of nitrogen atoms inside the carbon matrix [16]. It is also noteworthy that the metal-free catalysts often displayed higher activity and stability than metal and/or metal oxide catalysts. In a recent review, Su et al. [17] and Dai and co-workers [3] highlighted the advantages of using carbon-based metalfree catalysts for several catalytic reactions with an important advantage being the active site control. Recently, Peng and co-workers [18] reported that N-CNTs could be efficiently employed as a metal-free catalyst in the selective oxidation of benzyl alcohol to benzaldehyde with molecular oxygen. The $\mathrm{N}$-CNTs catalyst also exhibited extremely high stability in the recycling tests. Recently, Su and co-workers [19] also reported

\footnotetext{
* Corresponding author. Tel: +33-3-68 8526 67; Fax: +33-3-68 85 26 74; E-mail: yuefeng.liu@unistra.fr

\# Corresponding author. Tel: +33-3-68 85 26 67; Fax: +33-3-68 8526 74; E-mail: cuong.pham-huu@unistra.fr

DOI: 10.1016/S1872-2067(14)60116-9 | http://www.sciencedirect.com/science/journal/18722067 | Chin. J. Catal., Vol. 35, No. 6, June 2014
} 
that $s p^{2} \mathrm{~N}$-doped graphitic catalysts generated reactive oxygen species which allowed one to perform hydrocarbon activation even at room temperature. The big advantage of using these $\mathrm{N}$-CNTs catalysts versus the traditional metal/metal oxide supported ones is due to that the nitrogen species are well anchored within the catalyst structure and thus, problems linked with active phase sintering are unlikely to occur even under severe reaction conditions.

The aim of the present article is to report on the use of metal-free nitrogen-doped carbon nanotubes (N-CNTs) immobilized on a silicon carbide ( $\mathrm{SiC}$ ) extrudate host structure for catalytic applications. The macroscopic shaping of the catalyst allowed the avoidance of the problems of handling and pressure drop for applications in a fixed bed reactor [20]. The two probe reactions used in the present work to evaluate the catalytic activity of the N-CNTs/SiC catalyst were the selective oxidation of $\mathrm{H}_{2} \mathrm{~S}$ into elemental sulfur and the steam-free dehydrogenation of ethylbenzene into styrene. The influence of the reaction conditions on the catalytic performance was thoroughly investigated and the results were discussed using the characterization data. The stability of the catalysts was also evaluated in a long-term process.

\section{Experimental}

\subsection{Silicon carbide supports}

Silicon carbide $(\beta-\mathrm{SiC})$ in an extrudate shape was synthesized by a gas-solid reaction between $\mathrm{SiO}$ vapour and dispersed solid carbon. The detailed synthesis of the SiC-based materials was summarized in a recent review [21]. The $\beta$-SiC was synthesized by mixing microsized silicon powder with a carbon-containing resin. The paste was further shaped into the desired shape, i.e. extrudates, grains, beads, etc., before carburization. The carburization process was carried out under flowing argon at a temperature around $1350{ }^{\circ} \mathrm{C}$ for $1 \mathrm{~h}$. Examples of the medium to high surface area $\mathrm{SiC}$ with different size and shape synthesized by an industrial gas-solid process are presented in Fig. 1(a). The as-synthesized $\mathrm{SiC}$ was further calcined in air at $800{ }^{\circ} \mathrm{C}$ for $2 \mathrm{~h}$ to remove residual carbon. The resulting $\mathrm{SiC}$ material was thus partly covered with a thin layer of $\mathrm{SiO}_{2}$ and $\mathrm{SiO}_{x} \mathrm{C}_{y}$ (Fig. 1(b)), which could play the role of anchorage site for dispersing metal nanoparticles on its surface [22-24].

\subsection{Synthesis of the N-CNTs and N-CNTS/SiC composite}

The N-CNTs and N-CNTs/SiC composite (nitrogen-doped carbon nanotube decorated $\beta$-SiC extrudate) were synthesized by the chemical vapor deposition (CVD) method [25,26]. The synthesis of the N-CNTs/SiC composite was as follows. First, an aqueous solution containing $\mathrm{Fe}\left(\mathrm{NO}_{3}\right)_{3}$ ( $7 \mathrm{wt} \% \mathrm{Fe}$ ) was introduced onto the surface of $\mathrm{SiC}$ extrudates by incipient wetness impregnation. The $\mathrm{Fe} / \mathrm{SiC}$ sample was dried at room temperature overnight and oven-dried at $110{ }^{\circ} \mathrm{C}$ for $24 \mathrm{~h}$. It was then calcined in air at $350^{\circ} \mathrm{C}$ for $2 \mathrm{~h}$ to transform the nitrate precursor into the corresponding oxide. The $\mathrm{Fe}_{2} \mathrm{O}_{3} / \mathrm{SiC}$ catalyst was placed in a quartz reactor that was then put inside an elec- (a)
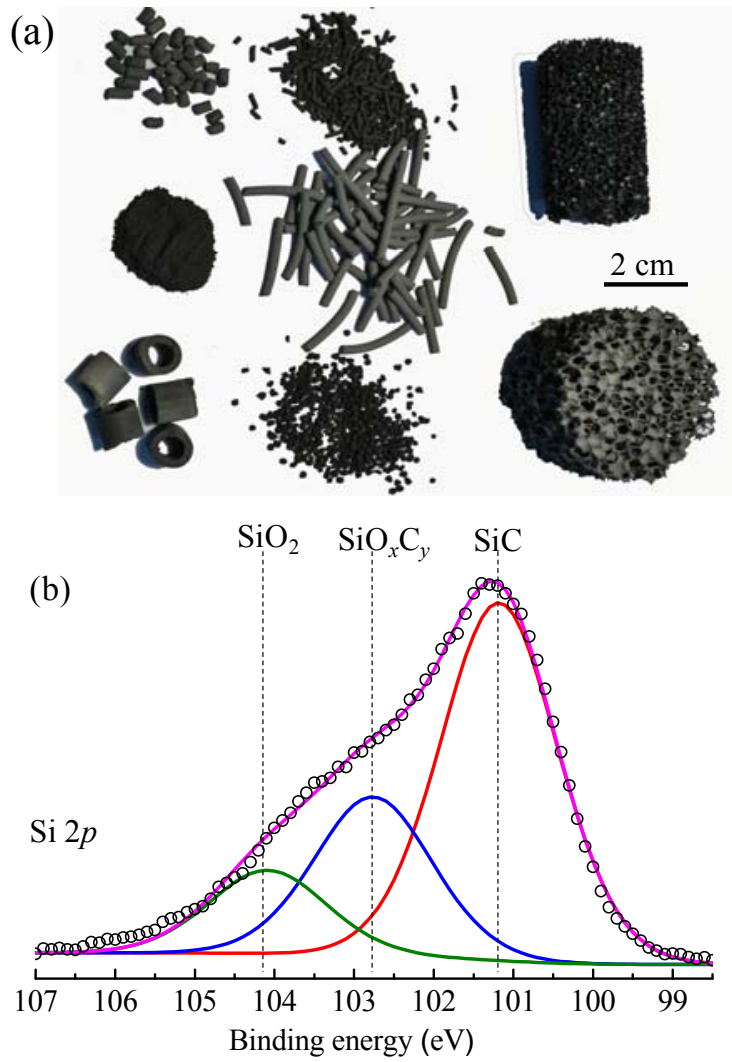

Fig. 1. (a) Macroscopic shapes, i.e., grains, extrudates, foams, and rings of silicon carbide synthesized by a gas-solid reaction (www.sicatcatalyst.com). (b) XPS Si $2 p$ of the SiC surface showing the presence of $\mathrm{SiC}, \mathrm{SiO}_{x} \mathrm{C}_{y}$, and $\mathrm{SiO}_{2}$.

tric furnace. The catalyst was reduced under $\mathrm{H}_{2}$ flow (200 $\mathrm{mL} / \mathrm{min}$ ) at $400{ }^{\circ} \mathrm{C}$ for $2 \mathrm{~h}$ and then, the temperature was raised to $750{ }^{\circ} \mathrm{C}$ (heating rate of $10{ }^{\circ} \mathrm{C} / \mathrm{min}$ ) and the $\mathrm{H}_{2}$ flow was replaced by a $\mathrm{C}_{2} \mathrm{H}_{6} / \mathrm{NH}_{3} / \mathrm{H}_{2}$ mixture. The X-ray diffraction (XRD) patterns of the Fe-based catalyst after calcination and reduction (not shown) confirmed the complete reduction of the $\mathrm{Fe}_{2} \mathrm{O}_{3}$ phase before the CNT-growth process. The $\mathrm{C}_{2} \mathrm{H}_{6}, \mathrm{NH}_{3}$, and $\mathrm{H}_{2}$ flow rates were 50,50 , and $20 \mathrm{~mL} / \mathrm{min}$, respectively. The synthesis was continued for $2 \mathrm{~h}$, and the reactor was cooled to room temperature under argon. Unsupported N-CNTs were synthesized by a commercial $\mathrm{Fe} / \mathrm{Al}_{2} \mathrm{O}_{3}$ catalyst instead of $\mathrm{Fe} / \mathrm{SiC}$. A similar process was used.

The N-CNTs-based composite was chemically treated before catalytic evaluation as described below. For the N-CNTs/SiC sample, the material was only treated with an acid solution $\left(\mathrm{HNO}_{3}, 65 \mathrm{vol} \%\right)$ at $80{ }^{\circ} \mathrm{C}$ for $12 \mathrm{~h}$ in order to remove the CNTgrowth catalyst. Transmission electron microscopy-electron energy loss spectroscopy (TEM-EELS) analysis of both samples indicated that the nitrogen concentration was higher in the arch region while a lower nitrogen concentration was observed on the tube wall [27], which confirmed a similar growth mode on both the unsupported and supported materials. For the $\mathrm{N}$-CNTs grown from the $\mathrm{Fe} / \mathrm{Al}_{2} \mathrm{O}_{3}$ catalyst, the synthesized product was treated by a $\mathrm{NaOH}(20 \mathrm{wt} \%)$ solution at $80^{\circ} \mathrm{C}$ for $24 \mathrm{~h}$ followed by an acid treatment $\left(\mathrm{HNO}_{3}, 65 \mathrm{vol} \%\right)$ at $80{ }^{\circ} \mathrm{C}$ for $12 \mathrm{~h}$ in order to remove the support and CNT-growth cata- 
lyst. The materials were washed thoroughly with distilled water between the treatment processes.

\subsection{Characterization}

The specific surface areas of the support and catalyst after reduction were determined on a Micromeritics sorptometer. The sample was outgassed at $250{ }^{\circ} \mathrm{C}$ under vacuum for $8 \mathrm{~h}$ to desorb moisture and adsorbed species on the surface. The measurements were carried out using $\mathrm{N}_{2}$ as adsorbate at liquid $\mathrm{N}_{2}$ temperature at relative pressures from 0.06 to 1.0 .

Scanning electron microscopy (SEM) was carried out on a JEOL $2600 \mathrm{~F}$ with a resolution of $5 \mathrm{~nm}$. The sample was deposited onto double face graphite tape to avoid the problem of charging during the analysis.

The TEM analysis was carried out on a JEOL $2100 \mathrm{~F}$ working at $200 \mathrm{kV}$ accelerated voltage, which was equipped with a probe corrector for spherical aberrations and a point-to-point resolution of $0.2 \mathrm{~nm}$. The sample was ground and then dispersed by ultrasonic treatment in an ethanol solution for $5 \mathrm{~min}$. A drop of the solution was deposited on a copper grid covered with a holey carbon membrane.

X-ray photoelectron spectroscopy (XPS) measurements of the support and catalyst were performed using a MULTILAB 2000 (THERMO) spectrometer equipped with an $\mathrm{Al} K_{\alpha}$ anode ( $h v=1486.6 \mathrm{eV}$ ) with $10 \mathrm{~min}$ of acquisition to achieve a good signal to noise ratio. Peak deconvolution was performed with the "Avantage" program from Thermoelectron Company. The C $1 s$ photoelectron binding energy was set at $284.6 \pm 0.2 \mathrm{eV}$ relative to the Fermi level and used as the reference to calibrate the other peak positions.

\subsection{Catalytic applications}

\subsubsection{Selective oxidation of $\mathrm{H}_{2} \mathrm{~S}$}

The catalytic selective oxidation of $\mathrm{H}_{2} \mathrm{~S}$ by oxygen (Eq. (1)) was carried out in an apparatus working isothermally at atmospheric pressure [11].

$$
\mathrm{H}_{2} \mathrm{~S}+1 / 2 \mathrm{O}_{2} \rightarrow 1 / n \mathrm{~S}_{n}+\mathrm{H}_{2} \mathrm{O} \quad \Delta H=-222 \mathrm{~kJ} / \mathrm{mol}
$$

An amount of catalyst, $300 \mathrm{mg}$ of N-CNTs or $1200 \mathrm{mg}$ $\mathrm{N}-\mathrm{CNTs} / \mathrm{SiC}$ (N-CNTs mass loading was $40 \mathrm{wt} \%$ which was also $300 \mathrm{mg}$ N-CNTs on the tested catalyst) was placed on silica wool in a tubular Pyrex reactor (i.d. $16 \mathrm{~mm}$ ), which was then placed inside a vertical tubular electrical furnace. The temperature was controlled by a K-type thermocouple and a Minicor regulator. The gas mixture of the reactant feed including $\mathrm{H}_{2} \mathrm{~S}$ (1 vol\%), $\mathrm{O}_{2}$ (2.5 vol\%), $\mathrm{H}_{2} \mathrm{O}$ (30 vol\%), and He (balance) was passed downward through the catalyst bed. The gases flow rates were monitored by Brooks 5850TR mass flow controllers linked to a control unit. The weight hourly space velocity (WHSV) was fixed at $0.6 \mathrm{~h}^{-1}$ and the $\mathrm{O}_{2} / \mathrm{H}_{2} \mathrm{~S}$ molar ratios used were $0.62,1.25$, and 2.5 .

The reaction was conducted in a continuous mode. The sulfur formed in the reaction was vaporized because of the high partial pressure of sulfur at these reaction temperatures, and it was condensed at the exit of the reactor in a trap maintained at room temperature. The analysis of the inlet and outlet gases was performed online using a Varian CP-3800 gas chromatograph (GC) equipped with a Chrompack CP-SilicaPLOT capillary column and a thermal catharometer detector (TCD), which allowed the detection of $\mathrm{O}_{2}, \mathrm{H}_{2} \mathrm{~S}, \mathrm{H}_{2} \mathrm{O}$, and $\mathrm{SO}_{2}$.

\subsubsection{Steam-free dehydrogenation of ethylbenzene}

The reaction was carried out in a fixed-bed continuous flow reactor under atmospheric pressure. The catalyst (150-300 $\mathrm{mg}$ ) was loaded onto a quartz fritted disk located inside a tubular quartz reactor (id: $8 \times 800 \mathrm{~mm}$ ). He was fed into the reactor at a flow rate of $30 \mathrm{~mL} / \mathrm{min}$ using a mass flow controller (BROOKS MFC) and passed through a glass evaporator filled with liquid EB maintained at $40{ }^{\circ} \mathrm{C}$ (EB partial pressure of 2922 $\mathrm{Pa}$ ) using a thermally regulated bath.

The reaction system was heated to $550{ }^{\circ} \mathrm{C}$ and kept for $2 \mathrm{~h}$ under He. The reactant flow (2.8 vol\% EB diluted in helium, total flow rate of $30 \mathrm{~mL} / \mathrm{min}$ ) was then fed to the reactor. The reactant and product (styrene (ST), benzene (BZ), and toluene (TOL) at the exit from the reactor was analyzed online with a PERICHROM (PR 2100) gas chromatograph equipped with a flame detector (FID) and CP WAX S2CB column which was previously calibrated. In order to avoid any possible condensation of the reactant or product, all tube lines were wrapped with a heating wire kept at $110^{\circ} \mathrm{C}$.

The ethylbenzene conversion $\left(X_{\mathrm{EB}}\right)$ and styrene selectivity $\left(S_{\mathrm{ST}}\right)$ were evaluated using Eqs. (2) and (3):

$$
\begin{gathered}
X_{\mathrm{EB}}=\frac{F_{0} C_{\mathrm{EB} \text {,inlet }}-F C_{\mathrm{EB}, \text { outlet }}}{F_{0} C_{\mathrm{EB} \text {,inlet }}} \times 100 \% \\
S_{\mathrm{ST}}=\frac{C_{\mathrm{ST}, \text { outlet }}}{C_{\mathrm{ST}, \text { outlet }}+C_{\mathrm{TOL}, \text { outlet }}+C_{\mathrm{BZ}, \text { outlet }}} \times 100 \%
\end{gathered}
$$

where $F$ and $F_{0}$ were the flow rates at the outlet and inlet, respectively, and $C_{\mathrm{EB}}, C_{\mathrm{ST}}, C_{\mathrm{TOL}}$, and $C_{\mathrm{BZ}}$ represented the concentrations of ethylbenzene, styrene, toluene, and benzene. The carbon balance amounted to $\geq 96 \%$ in all investigations. The results were obtained after $15 \mathrm{~h}$ on stream with a stable catalytic performance at the testing conditions.

\section{Results and discussion}

\subsection{N-CNTs/SiC characterization}

The specific surface area of the N-CNTs/SiC and related samples were obtained using $\mathrm{N}_{2}$ adsorption isotherms at -196 ${ }^{\circ} \mathrm{C}$, which are displayed in Fig. 2. The $\mathrm{N}_{2}$ adsorption isotherms of both the N-CNTs and N-CNTs/SiC samples were Type IV isotherms in the relative pressure region between 0.45 and 1.0, confirming the macroporous and mesoporous architecture of the samples. The pristine $\beta$-SiC extrudate demonstrated a Type IV isotherm in the relative pressure region between 0.85 and 1.0 , revealing the relative low surface area of the SiC support $\left(25 \mathrm{~m}^{2} / \mathrm{g}\right)$. It is interesting to note that the introduction of the $\mathrm{N}-\mathrm{CNT}$ on the SiC host surface led to a significant increase of the composite specific surface area, from $25 \mathrm{~m}^{2} / \mathrm{g}$ to more than $150 \mathrm{~m}^{2} / \mathrm{g}$ with only $40 \%$ weight loading of N-CNTs on the SiC surface. The bulk densities of N-CNTs and N-CNTs/SiC were 143 and $750 \mathrm{~kg} / \mathrm{m}^{3}$, respectively. The specific surface area in- 


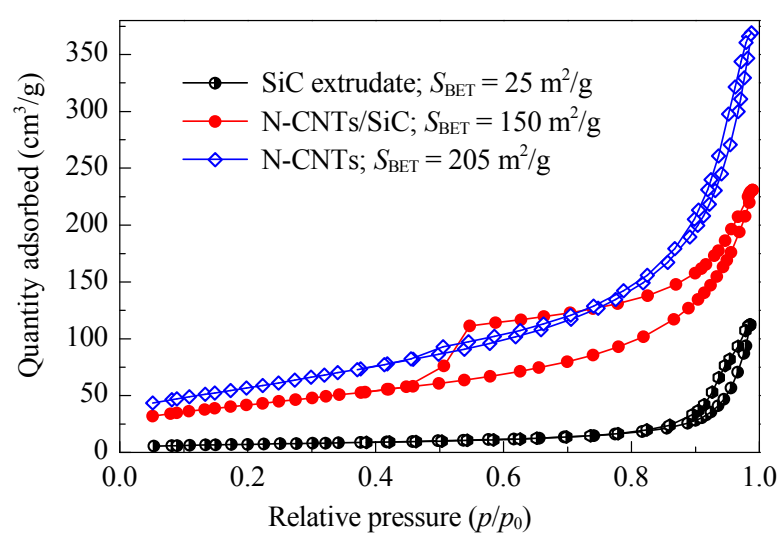

Fig. 2. $\mathrm{N}_{2}$ adsorption-desorption isotherms of SiC extrudate, N-CNTs/ $\mathrm{SiC}$, and N-CNTs.

crease was attributed to the presence of N-CNTs with a high intrinsic surface area $[6,7,13,25]$.

SEM analysis was extensively employed to characterize the final composite morphology and the coverage of the SiC host structure by the N-CNTs (Fig. 3(a) and (b)). The low magnification SEM micrographs (Fig. 3(a) and inset) indicated that the SiC surface was completely covered by a dense and homogeneous layer of entangled carbon nanotubes that provided a high density of active sites and a low diffusion resistance catalyst network for performing the selective oxidation reaction. The microstructure of the N-CNTs/SiC catalyst was also investigated by TEM. Representative TEM micrographs are presented in Fig. 3(c) and (d). The TEM analysis (Fig. 3(c)) confirmed the periodical bamboo-like structure of the nanotube, which is typical for CNTs doped with nitrogen atoms [28-30]. The low magnification TEM analysis indicated the complete absence of carbon nanoparticles, which again confirmed the high selectivity of the synthesis for the formation of N-CNTs. The high reso-
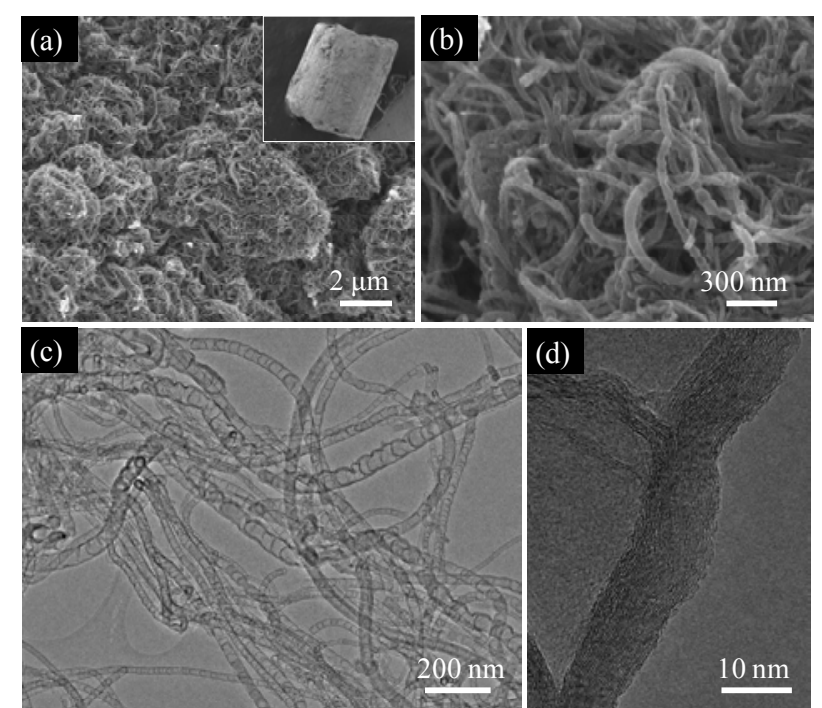

Fig. 3. SEM micrographs of the N-CNTs/SiC (a, b) composites showing the high coverage of the SiC surface by the N-CNTs network (Inset: Digital photo of SiC extrudate covered with $\mathrm{N}$-doped carbon nanotubes). TEM micrograph of the N-CNTs with a bamboo-like morphology (c) and a high resolution TEM image showing N-CNTs free of amorphous carbon (d). lution TEM micrographs (Fig. 3(d)) indicated the almost complete absence of an amorphous carbon layer and no residual iron CNT-growth catalyst on the outer surface of the synthesized N-CNTs.

The average N-CNTs diameter of N-CNTs/SiC was also investigated by a statistical analysis using the TEM images. The diameter distribution is displayed in Fig. 4. The corresponding diameter distribution for N-CNTs is also presented in the same figure for comparison. The results showed that the N-CNTs synthesized from the alumina-based catalyst exhibited a much narrower diameter distribution centered between 20 and 40 $\mathrm{nm}$, while those synthesized from the SiC-based catalyst showed a much wider diameter distribution ranging from 20 to $80 \mathrm{~nm}$. This result can be explained by the fact that on $\mathrm{SiC}$, the Fe-based catalyst was sintered in the course of the synthesis due to the weak metal-support interaction with the SiC surface compared to that of iron-alumina.

XPS was utilized to get quantitative information on the surface composition of the N-CNTs-based materials (Fig. 5). The XPS analysis was performed after the chemical treatment for removing the CNT-growth catalyst on the N-CNTs and N-CNTs/SiC samples. The broad scan spectra in Fig. 5(a) clearly revealed that nitrogen, oxygen and carbon were present on the surface of the N-CNTs and N-CNTs/SiC samples. The N $1 s$ XPS showed that N-CNTs/SiC contained 4.1 atom\% nitrogen (Fig. 5(b) and (d)). The high resolution XPS N 1s spectrum (Fig. 5(b)) showed the presence of several nitrogen-bonded carbon species on the N-CNTs/SiC sample: pyridinic (398.7 eV), pyrrolic (400.2 eV), quaternary (401.7 eV), and an oxidized type of pyridinic nitrogen (405.0 eV) [31-34]. The N 1s XPS spectrum of the N-CNTs sample (same synthesis conditions as N-CNTs/SiC) exhibited also similar species. The N-CNTs/SiC sample had a higher total $\mathrm{N}$ content and also more N-pyridinic species compared to the N-CNTs sample $333.5 \%$ of N-CNTs/SiC compared to $15.8 \%$ of $\mathrm{N}$-CNTs).

The presence of Fe particles on the surface of N-CNTs was also investigated by XPS. The Fe $2 p$ XPS spectra of the N-CNTs/SiC and N-CNTs-750 catalysts are shown in Fig. 5(c). The atomic percentages of Fe in N-CNTs/SiC and N-CNTs (not shown) measured by XPS were very low. The XPS analysis also

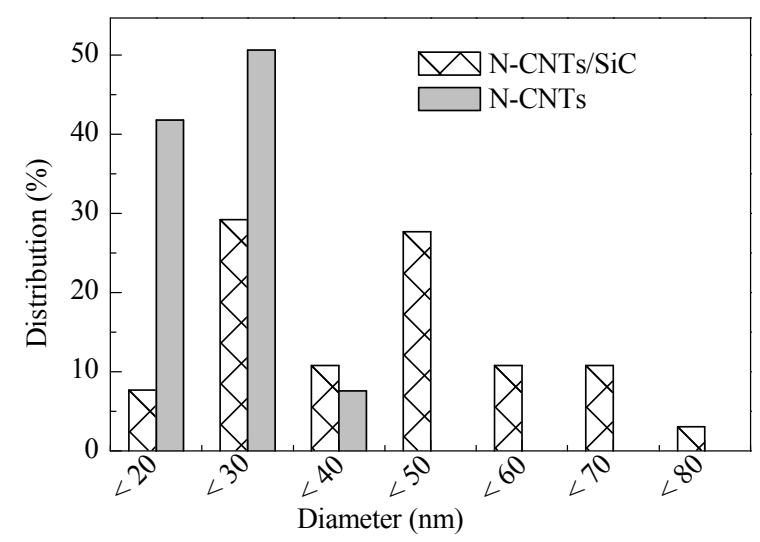

Fig. 4. Diameter distribution of $\mathrm{N}$-doped carbon nanotubes synthesized from the $\gamma-\mathrm{Al}_{2} \mathrm{O}_{3}$ and $\mathrm{SiC}$-based catalysts determined from a statistical TEM analysis. 

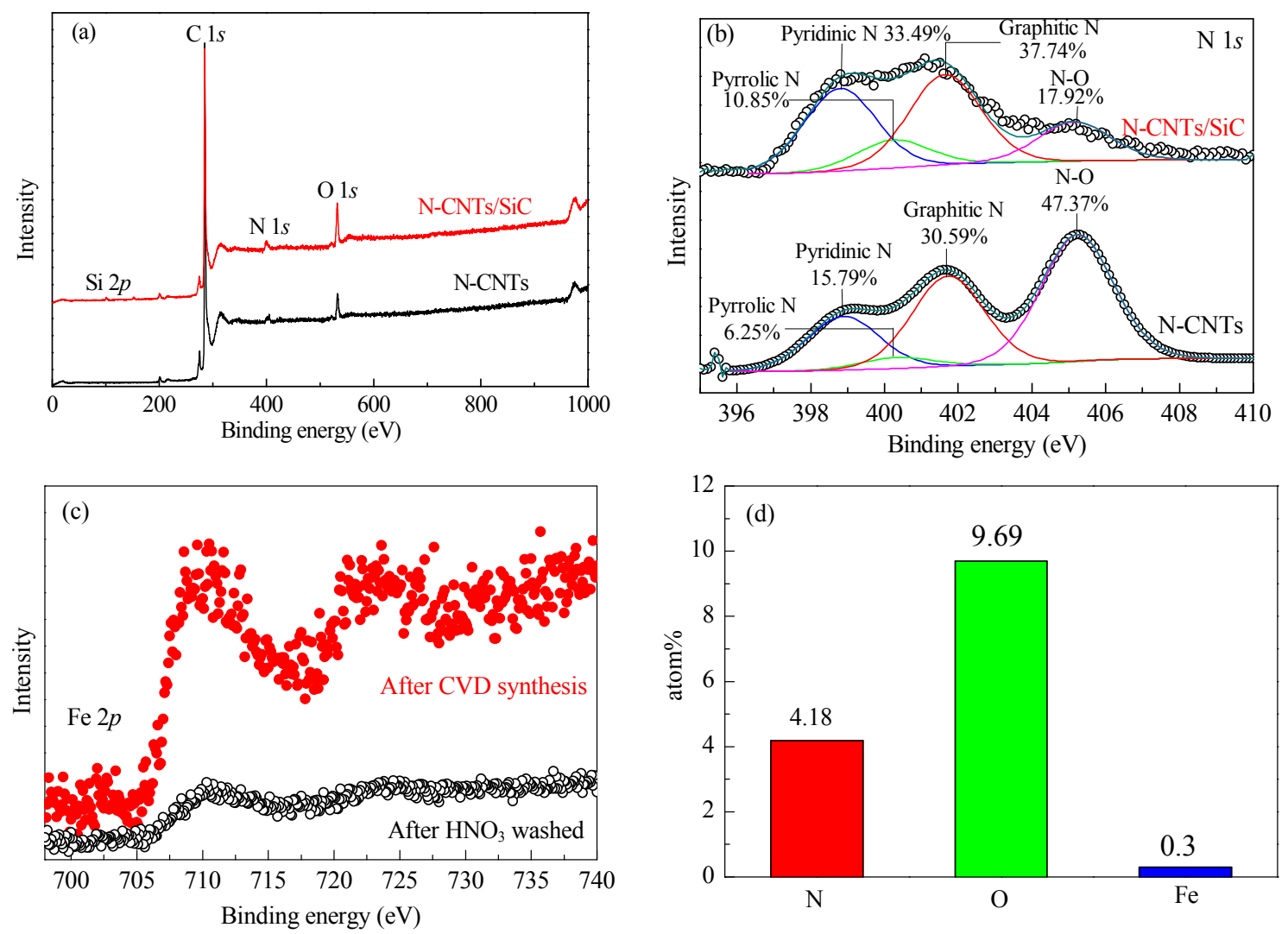

Fig. 5. XPS scan (a) and N $1 s$ XPS spectra (b) of the N-CNTs/SiC and N-CNTs catalysts after acid treatment in $\mathrm{HNO}_{3}\left(65\right.$ vol\%) at $80{ }^{\circ} \mathrm{C}$ for $12 \mathrm{~h}$. (c) Fe $2 p$ XPS spectra recorded from the sample after CVD synthesis and after acid treatment. (d) Percentages measured by XPS of nitrogen, oxygen, and residual iron in the $\mathrm{N}-\mathrm{CNTs} / \mathrm{SiC}$ material after the acid treatment.

confirmed the complete removal of the iron CNT-growth catalyst (7 wt $\%$ ) after the acid treatment $(0.3$ atom\%, Fig. $5(d))$. One cannot exclude the presence of some residual iron CNT-growth catalyst inside the N-CNTs channels which were not accessible during the acid treatment. According to previous results, these residual iron NPs were also not accessible to the reactant during the catalytic reaction $[35,36]$.

\subsection{Selective oxidation of $\mathrm{H}_{2} \mathrm{~S}$}

\subsubsection{Desulfurization performance of the $\mathrm{N}$-CNTS/SiC and $\mathrm{Fe}_{2} \mathrm{O}_{3}(3 \%) / \mathrm{SiC}$ catalysts}

For comparison, the catalytic desulfurization performance of the $\mathrm{Fe}_{2} \mathrm{O}_{3}(3 \%) / \mathrm{SiC}$ extrudate catalyst, which is among the most active catalyst for the selective oxidation of $\mathrm{H}_{2} \mathrm{~S}[37,38]$, and that of N-CNTs/SiC are reported in Fig. 6. The result showed that all the tested catalysts exhibited high stability as a function of time on stream. It can be seen that under the same reaction conditions, $\mathrm{N}-\mathrm{CNTs} / \mathrm{SiC}$ exhibited a conversion of $97 \%$ compared to $<20 \%$ for the $\mathrm{Fe}_{2} \mathrm{O}_{3}(3 \%) / \mathrm{SiC}$ catalyst. The result clearly indicated that the N-CNTs/SiC metal-free catalyst was 4 times higher in activity than the most active $\mathrm{Fe}_{2} \mathrm{O}_{3}(3 \%) / \mathrm{SiC}$ catalyst reported for performing the selective oxidation of $\mathrm{H}_{2} \mathrm{~S}$ into elemental sulfur in a low reaction temperature range and under a high space velocity. On the N-CNTs/SiC catalyst, the large surface area combined with the nanoscopic size of the carbon nanotubes significantly improved the accessibility to the active site by the reactant, as all the active sites were localized on these nanoscopic antenna, leading to a high desulfurization activity. Similar results were also obtained with a cobalt catalyst deposited on a low surface area alumina decorated with carbon nanotubes for Fischer-Tropsch synthesis [36]. The Fischer-Tropsch activity was greatly improved compared to the alumina-based catalyst due to the large surface area of the carbon-based catalyst. In our work, the difference in the specific surface area between the two catalysts, i.e., $40 \mathrm{~m}^{2} / \mathrm{g}$ for the

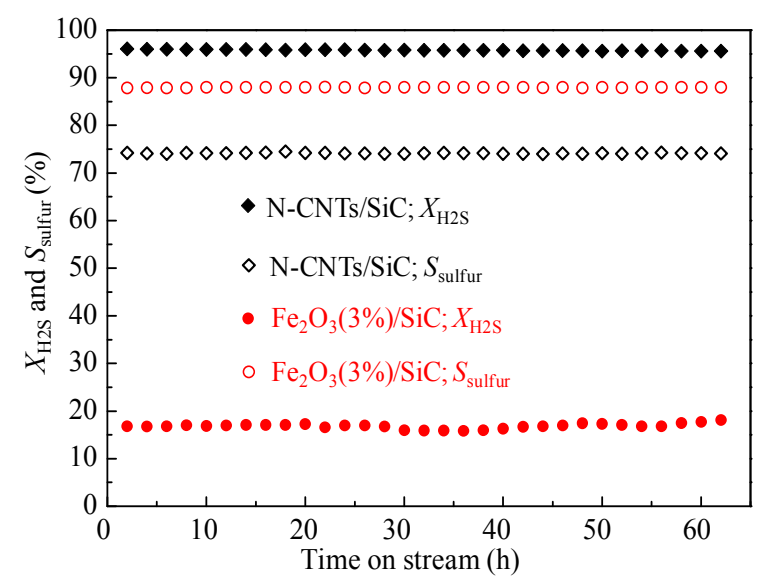

Fig. 6. Desulfurization conversion $\left(X_{\mathrm{H} 2 \mathrm{~S}}\right)$ and sulfur selectivity $\left(S_{\text {sulfur }}\right)$ on the $\mathrm{N}$-CNTs/SiC and $\mathrm{Fe}_{2} \mathrm{O}_{3}(3 \%) / \mathrm{SiC}$ catalysts. Reaction conditions: $\mathrm{O}_{2}$-to- $\mathrm{H}_{2} \mathrm{~S}$ molar ratio $=2.5$, reaction temperature $=190^{\circ} \mathrm{C}, \mathrm{WHSV}=0.6$ $\mathrm{h}^{-1}$. 
$\mathrm{Fe}_{2} \mathrm{O}_{3} / \mathrm{SiC}$ and $150 \mathrm{~m}^{2} / \mathrm{g}$ for the N-CNTs/SiC catalyst, also significantly contributed to the enhancement of the desulfurization performance by the N-CNTs/SiC catalyst. The low desulfurization activity of the $\mathrm{Fe}_{2} \mathrm{O}_{3}(3 \%) / \mathrm{SiC}$ catalyst can be attributed to the fact that the Fe-based catalyst exhibited a lower specific surface area than the N-CNTs/SiC catalyst and also that most of the Fe active sites were localized within the pore of the support and thus, remained less accessible to the reactant as the internal diffusion of the reactant inside the pores was required for the reaction.

On the other hand, the sulfur selectivity of the N-CNTs based catalysts was slightly lower than that of the Fe-based catalyst, i.e., $75 \%$ instead of $88 \%$. This low sulfur selectivity was attributed to the high activity of the N-CNTs, which further oxidized the sulfur into $\mathrm{SO}_{2}$ in the presence of excess oxygen in the stream.

The longer residence time of the sulfur intermediate within the N-CNTs layer would also favor the secondary oxidation reaction to yield $\mathrm{SO}_{2}$ and thus, lead to a lower selectivity. According to this result, one would expect that the N-CNTs density and thickness would play a significant role in the desulfurization performance. Work is ongoing to find a new structured metal-free catalyst with better activity and with high selectivity by replacing the N-CNTs by a nitrogen-doped carbon composite with a large surface area and short diffusion characteristic length, i.e., mesoporous doped carbon from the thermal decomposition of polymerized ionic liquids (PILs) [39].

\subsubsection{Influence of the $\mathrm{O}_{2}$-to- $\mathrm{H}_{2} \mathrm{~S}$ molar ratio}

The influence of the $\mathrm{O}_{2}$-to- $\mathrm{H}_{2} \mathrm{~S}$ molar ratio on the desulfurization performance was also studied to evaluate the ability of the N-CNTs to generate active oxygen species for oxidizing $\mathrm{H}_{2} \mathrm{~S}$. The results obtained at different $\mathrm{O}_{2}$-to- $\mathrm{H}_{2} \mathrm{~S}$ molar ratios, i.e., 2.5, 1.25 and 0.62 , as a function of time on stream are presented in Fig. 7. A decrease of the $\mathrm{O}_{2}-\mathrm{to}-\mathrm{H}_{2} \mathrm{~S}$ molar ratio led to a slight decrease of the desulfurization performance without any observable deactivation as a function of time on stream. On the other hand, the sulfur selectivity steadily increased with decreasing $\mathrm{O}_{2}$-to- $\mathrm{H}_{2} \mathrm{~S}$ molar ratio. The sulfur selectivity increase was attributed to the low oxygen partial pressure which prevented the successive oxidation of the sulfur into $\mathrm{SO}_{2}$. The slight

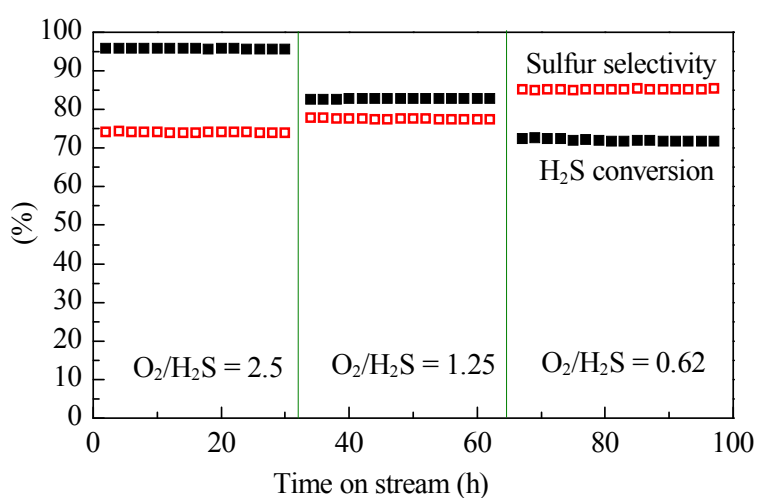

Fig. 7. Desulfurization performance on the N-CNTs/SiC catalyst at different $\mathrm{O}_{2}$-to- $\mathrm{H}_{2} \mathrm{~S}$ molar ratios. Reaction conditions: catalyst weight $=0.3$ g, temperature $=190^{\circ} \mathrm{C}, \mathrm{WHSV}=0.6 \mathrm{~h}^{-1}$. decrease in the desulfurization performance on decreasing the $\mathrm{O}_{2}$-to- $\mathrm{H}_{2} \mathrm{~S}$ molar ratio from 2.5 to 0.62 observed here was evidence of the high activity of the nitrogen-modified carbon sites for oxygen dissociation, which provided enough oxygen to perform the selective oxidation of $\mathrm{H}_{2} \mathrm{~S}$ even at a low oxygen concentration and a high space velocity. This phenomenon is similar to the oxygen dissociation mechanism reported on N-CNTs for the ORR [40]. It is noteworthy that the desulfurization performance remained high, ca. 70\%, despite the difficult reaction conditions, i.e., high space velocity and low $\mathrm{O}_{2}$-to- $\mathrm{H}_{2} \mathrm{~S}$ molar ratio. A desulfurization reaction carried out on supported Fe-based catalysts at a higher reaction temperature and lower WHSV has shown that at a low $\mathrm{O}_{2}-$ to- $\mathrm{H}_{2} \mathrm{~S}$ molar ratio, the $\mathrm{H}_{2} \mathrm{~S}$ conversion was much decreased due to the lack of active oxygen species for the reaction [41].

\subsection{Stream-free dehydrogenation of ethylbenzene (EB)}

We also investigated the stream-free dehydrogenation of ethylbenzene using the $\mathrm{N}-\mathrm{CNTs} / \mathrm{SiC}$ material as a metal-free catalyst. It is of interest to develop hierarchical N-CNTs/SiC materials as a robust EB dehydrogenation catalyst for replacing the traditional metal or metal oxide catalysts in the industrial process $[13,42]$. The catalytic activities of N-CNTs/SiC, N-CNTs and pristine $\mathrm{SiC}$ were evaluated in a fixed bed reactor under atmospheric pressure at $550{ }^{\circ} \mathrm{C}$. A typical industrial $\mathrm{K}-\mathrm{Fe}_{2} \mathrm{O}_{3}$ catalyst was tested at the same conditions to allow a direct comparison with the N-CNTs/SiC catalyst. Figure 8(a) presents
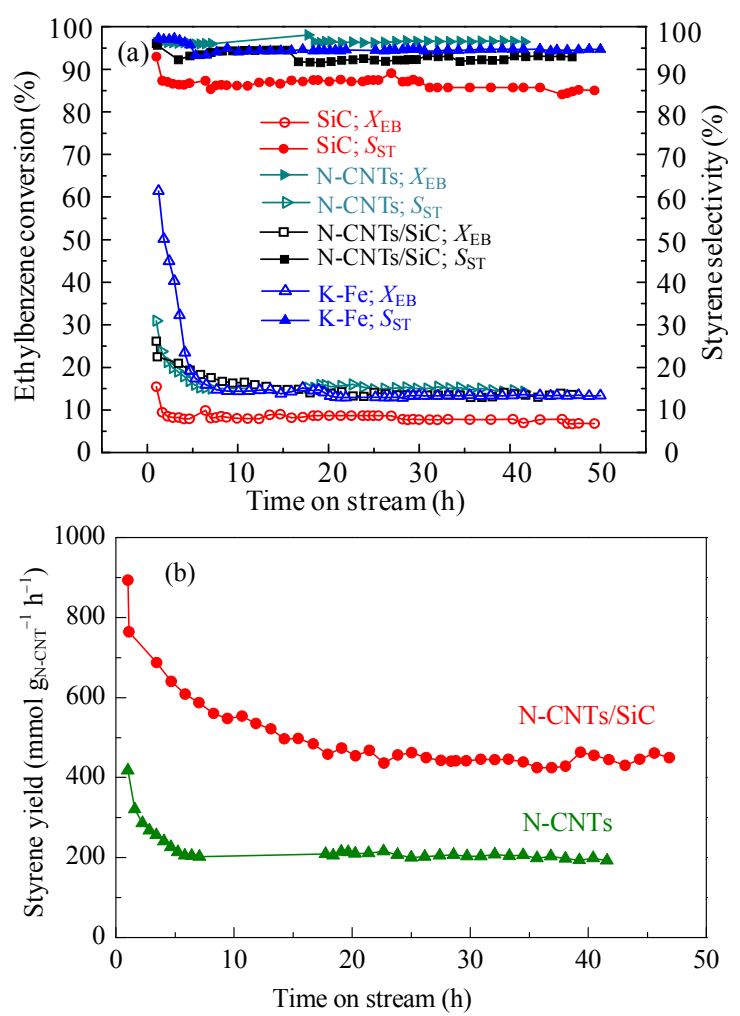

Fig. 8. (a) Ethylbenzene dehydrogenation activity over N-CNTs/SiC, N-CNTs, pristine SiC, and commercial K-Fe catalyst. (b) Styrene specific rate of N-CNTs-based catalysts under steady state. Reaction conditions: catalyst $0.3 \mathrm{~g}, 550{ }^{\circ} \mathrm{C}, 2.8 \% \mathrm{~EB}$ in $\mathrm{He}, 30 \mathrm{~mL} / \mathrm{min}$. 
the catalytic activity of all the catalysts as function of time on stream. The conversion of ethylbenzene over the pristine SiC reached $8.1 \%$ after $10 \mathrm{~h}$ test with the styrene selectivity of $88.2 \%$. For N-CNTs/SiC, $14.0 \%$ EB conversion and $95.0 \%$ styrene selectivity were obtained, which were similar to those of the N-CNTs (pure nitrogen-doped carbon nanotubes) and commercial $\mathrm{K}-\mathrm{Fe}_{2} \mathrm{O}_{3}$ catalysts (Fig. 8(a)). The same activity obtained with the N-CNTs/SiC-750 catalyst compared to the commercial catalyst indicated that this metal-free catalyst is a promising candidate for the stream-free EB dehydrogenation reaction. It is worth noting that only $40 \%$ mass loading of $\mathrm{N}$-CNTs was used on the N-CNTs/SiC sample, which displayed the same EB conversion as the N-CNTs catalyst. As shown in Fig. 8(b), the specific rate at the steady state activity of the $\mathrm{N}-\mathrm{CNTs} / \mathrm{SiC}$ catalyst $(459.87 \mathrm{mmol} /(\mathrm{g} \cdot \mathrm{h})$ ) was 2.3 times higher than that of the N-CNTs catalyst, which was expressed as the amount of styrene produced per gram N-CNTs per hour. These data also confirmed that the highly accessible macroscopic structured N-CNTs/SiC enhanced the contact between the active site and reactant as mentioned above.

\section{Conclusions}

Nitrogen-doped carbon nanotubes supported on a macroscopic host structure of $\mathrm{SiC}$ was an active and selective metal-free catalyst for the low temperature oxidation of $\mathrm{H}_{2} \mathrm{~S}$ and for the steam-free dehydrogenation of ethylbenzene. The macroscopic shaping of the catalyst enabled avoiding the problems of handling and transport of nanoscopic bulk N-CNTs catalysts. In addition, this hybrid metal-free catalyst with a controlled macroscopic shape can be efficiently employed in a fixed bed configuration without the problem of a large pressure drop across the catalytic bed. The results showed that the hierarchical nitrogen-doped carbon materials with controlled macroscopic shaping were an efficient metal-free catalyst for several reactions of interest. Work is ongoing to optimize the DH activity of the catalyst by decorating the N-CNTs surface with nanodiamond nanoparticles.

\section{Acknowledgments}

The present work is financially supported by a European project (FREECATS) under a contract number NMP-2011-2.2-4 "Novel materials for replacement of strategic or scarce raw materials". DVC would like to thank the Vietnamese government for the grant during his stay at the ICPEES. LTP would like to thank the EU for the grant during his postdoctoral stay at the ICPEES. The SiC samples were supplied by SICAT Co. (www.sicatcatalyst.com) within the framework of the FREECATS project. The TEM and SEM analysis were performed at the facilities of the IPCMS (UMR 7504 CNRS-University of Strasbourg) and S. Moldovan (IPCMS) and T. Romero (ICPEES) are gratefully acknowledged for performing the analysis. P. Bernhardt (ICPEES) is also gratefully acknowledged for the XPS analysis.

\section{References}

[1] Yasuda S, Yu L, Kima J, Murakoshi K. Chem Commun, 2013, 49: 9627

[2] Tuci G, Zafferoni C, D’Ambrosio P, Caporali S, Ceppatelli M, Rossin A, Tsoufis T, Innocenti M, Giambastiani G. ACS Catal, 2013, 3: 2108

[3] Qu L T, Liu Y, Baek J-B, Dai L M. ACS Nano, 2010, 4: 1321

[4] Nederlof C, Kapteijn F, Makkee M. Appl Catal A, 2012, 417-418: 163

[5] Bégin D, Ulrich G, Amadou J, Su D S. Pham-Huu C, Ziessel R. J Mol Catal A, 2009, 302: 119

[6] Chen C L, Zhang J, Zhang B S, Yu C L, Peng F, Su D S. Chem Commun, 2013, 49: 8151

[7] Amadou J, Chizari K, Houllé M, Janowska I, Ersen O, Bégin D, Pham-Huu C. Catal Today, 2008, 138: 62

[8] Villa A, Tessonnier J P, Majoulet O, Su D S, Schlögl R. Chem Commun, 2009: 4405

[9] Villa A, Tessonnier J P, Majoulet O, Su D S, R. Schlögl R. ChemSusChem, 2010, 3: 241

[10] Cao Y H, Yu H, Tan J, Peng F, Wang H J, Li J, Zheng W X, Wong N B. Carbon, 2013, 57: 433

[11] Chizari K, Deneuve A, Ersen O, Florea I, Liu Y, Edouard D, Janowska T, Begin D, Pham-Huu C. ChemSusChem, 2012, 5: 102

\section{Graphical Abstract}

Chin. J. Catal., 2014, 35: 906-913 doi: 10.1016/S1872-2067(14)60116-9

\author{
Nitrogen-doped carbon nanotubes on silicon carbide as a \\ metal-free catalyst \\ Cuong Duong-Viet, Housseinou Ba, Yuefeng Liu*, Lai Truong-Phuoc, \\ Jean-Mario Nhut, Cuong Pham-Huu* \\ University of Strasbourg, France; \\ Hanoi University of Mining and Geology, Viet Nam
}

A hierarchical metal-free catalyst consisting of a nitrogen-doped carbon nanotube layer coated on a macroscopic beta-SiC host matrix was synthesized which exhibited high activity and stability for the selective oxidation of $\mathrm{H}_{2} \mathrm{~S}$ and steam-free dehydrogenation of ethylbenzene.

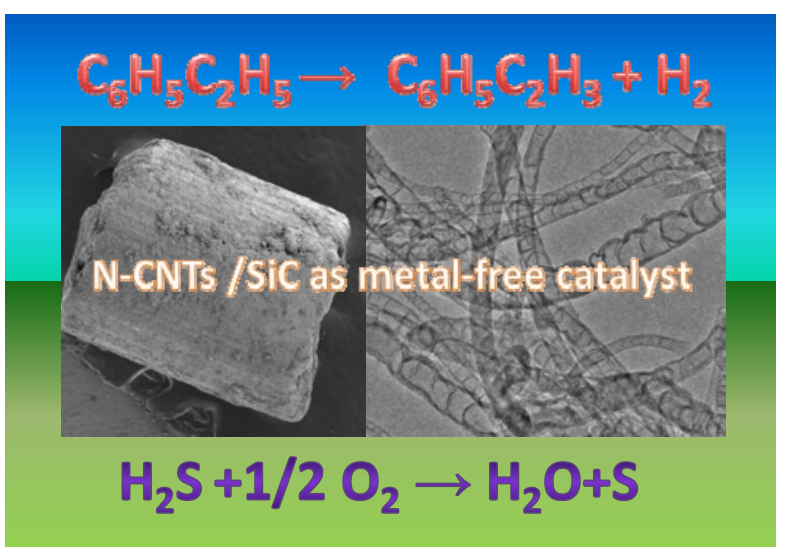


[12] Long J L, Xie X Q Xu J, Gu Q, Chen L M, Wang X X. ACS Catal, 2012, 2: 622

[13] Su D S, Perathoner S, Centi G. Chem Rev, 2013, 113: 5782

[14] Wang H B, Maiyalagan T, Wang X. ACS Catal, 2012, 2: 781

[15] Yu D S, Nagelli E, Du F, Dai L M. J Phys Chem Lett, 2010, 1: 2165

[16] Peng S, Cho K. Nano Lett, 2003, 3: 513

[17] Su D S, Zhang J, Frank B, Thomas A, Wang X C, Paraknowitsch J, Schlögl R. ChemSusChem, 2010, 3:169

[18] Luo J, Peng F, Wang H, Yu H. Catal Commun, 2013, 39: 44

[19] Gao Y J, Hu G, Zhong J, Shi Z J, Zhu Y S, Su D S, Wang J G, Bao X H, Ma D. Angew Chem Int Ed, 2013, 52: 2109

[20] Liu Y F, Nguyen L D, Truong-Huu T, Liu Y, Romero T, Janowska I, Begin D, Pham-Huu C. Mater Lett, 2012, 79: 128

[21] Nguyen P, Pham C. Appl Catal A, 2011, 391: 443

[22] Deneuve A, Florea I, Ersen O, Nguyen P, Pham C, Begin D, Edouard D, Ledoux M J, Pham-Huu C. Appl Catal A, 2010, 385: 52

[23] Florea I, Ersen O, Hirlimann C, Roiban L, Deneuve A, Houllé M, Janowska I, Nguyen P, Pham C, Pham-Huu C. Nanoscale, 2010, 2: 2668

[24] Liu Y F, Ersen O, Meny C, Luck F, Pham-Huu C. ChemSusChem, 2014, DOI: $10.1002 /$ cssc.201300921

[25] Chizari K, Janowska I, Houllé M, Florea I, Ersen O, Romero T, Bernhardt P, Ledoux M J, Pham-Huu C. Appl Catal A, 2010, 380: 72

[26] Louis B, Gulino G, Vieira R, Amadou J, Dintzer T, Galvagno S, Centi G, Ledoux MJ, Pham-Huu C. Catal Today, 2005, 102-103: 23

[27] Florea I, Ersen O, Arenal R, Ihiawakrim D, Messaoudi C, Chizari K, Janowska I, Pham-Huu C. J Am Chem Soc, 2012, 134: 9672

[28] Terrones M, Benito A M, Manteca-DiegoC, Hsu W K, Osman O I,
Hare J P, Reid D G, Terrones H, Cheetham A K, Prassides K, Kroto H W, Walton D R M. Chem Phys Lett, 1996, 257: 576

[29] Zhong D Y, Lin S, Zhang G Y, Wang E G. J Appl Phys, 2001, 89: 5939

[30] Chizari K, Vena A, Laurentius L, Sundararaj U. Carbon, 2014, 68: 369

[31] Biniak S, Szymanski G, Siedlewski J, Wiatkoski A. Carbon, 1997, 35 : 1799

[32] Choi H C, Park J, Kim B.J Phys Chem B, 2005, 109: 4333

[33] Choi H C, SBae S Y, Park J, Seo K, Kim C, Kim B, Song H J, Shin H J. Appl Phys Lett, 2004, 85: 5742

[34] Strelko V V, Kartel N T, Dukhno I N, Kuts V S, Clarkson R B, Odintsov B M. Surf Sci, 2004, 548: 281

[35] Gulino G, Vieira R, Amadou J, Nguyen P, Ledoux M J, Galvagno S, Centi G, Pham-Huu C. Appl Catal A, 2005, 279: 89

[36] Liu Y F, Dintzer T, Ersen O, Pham-Huu C. J Energy Chem, 2013, 22: 279

[37] Keller N, Pham-Huu C, Crouzet C, Ledoux M J, Savin-Poncet S, Nougayrede J B, Bousquet J. Catal Today, 1999, 53: 535

[38] Nguyen P, Edouard D, Nhut J M, Ledoux M J, Pham C, Pham-Huu C. Appl Catal B, 2007, 76: 300

[39] Zhao Q Feillinger T P, Antoneitti M, Yuan J. J Mater Chem A, 2013, 1: 5113

[40] Gong K P, Du F, Xia Z H, Durstock M, Dai L M. Science, 2009, 323: 760

[41] Keller N, Pham-Huu C, Ledoux M J. Appl Catal A, 2001, 217: 205

[42] Zhang J, Su D S, Blume R, Schlogl R, Wang R, Yang X G, Gajovic A. Angew Chem Int Ed, 2010, 49: 8640 